\title{
Developmental competence of water buffalo oocytes in a synthetic oviductal fluid base medium
}

\author{
Lerma C. Ocampo ${ }^{1,2}$, Elfren F. Celestino Jr ${ }^{3}$, Flocerfida P. Aquino ${ }^{1}$ and Marlon B. Ocampo ${ }^{1,3}$ \\ ${ }^{1}$ Philippine Carabao Center, Reproductive Biotechnology Unit, Science City of Muñoz, Nueva Ecija, Philippines, \\ ${ }^{2}$ Department of Biological Sciences, Central Luzon State University, Science City of Muñoz, Nueva Ecija, ${ }^{3}$ College \\ of Veterinary Science and Medicine, Central Luzon State University, Science City of Muñoz, Nueva Ecija, \\ Philippines, 3120
}

Article history

Received: 21 May, 2016

Revised: 28 Jun, 2016

Accepted: $20 \mathrm{Jul}, 2016$

\begin{abstract}
In this study, in vitro derived (oocytes from ovaries of slaughtered buffalo cows) and in vivo derived (oocytes collected through TUFA from living buffalo cows) oocytes were assessed on their ability to acquire the necessary developmental competence in the production of blastocyst stage embryos when cultured in culture systems using a complex/serial culture media or a single based medium from maturation to culture. In vitro derived oocytes ability to complete the $1^{\text {st }}$ meiotic division (nuclear maturation) showed no difference when cultured in either culture systems (82.6-83.1\%) but was higher compared to in vivo derived oocytes (62.3-74.4\%). The cleavage rate of in vivo derived oocytes (78.7-79.2\%) was significantly higher than in vitro derived oocytes (59.4-62.9\%). Significantly higher blastocyst formation rate was observed from in vivo derived oocytes cultured in a single based culture system (31.1\%). Overall, the results showed the usefulness and practicality of using a single synthetic oviductal fluid based medium for supporting buffalo oocytes acquisition of developmental competence in an in vitro culture system.

Keywords: Synthetic oviductal fluid; maturation; embryo development
\end{abstract}

To cite this article: Ocampo LC, EF Celestino Jr, FP Aquino and MB Ocampo, 2016. Developmental competence of water buffalo oocytes in a synthetic oviductal fluid base medium. Res. Opin. Anim. Vet. Sci., 6(6): $173-177$.

\section{Introduction}

Mammalian oocytes have ability to achieve full developmental competence up to the blastocyst stage following in vitro fertilization requires a carefully regulated environment which is dependent on the compositions of the medium used. Oftentimes, the variabilities observed on the results under the in vitro systems could be traced back on the differences on the media (e.g., type, batches, lot) used and its supplementations. Thus, a need for a single culture system that would support the oocytes acquisition of competence for complete maturation, the resulting zygotes development past the "cell-block" stage up to the blastocyst stage is imperative. The developing oocyte in vivo is normally exposed to a continually changing microenvironment to become developmentally competent. As it finds its way into the oviductal fluids after the ovulation event, an equally competent fully capacitated sperm similarly exposed to

\footnotetext{
*Corresponding author: Lerma C. Ocampo, Philippine Carabao Center, Reproductive Biotechnology Unit, Science City of Muñoz, Nueva Ecija, Philippines; E-mail: ocampolerma040661@gmail.com
} 
the tubal microenvironment completes the whole fertilization process. In vitro studies on the use of formulated culture media preparations were so designed to mimic the natural environment to as closely as possible where the oocytes are normally exposed to. These in vitro culture media provide the stage-specific nutrient requirements of the fertilized oocytes for optimum development to occur until they become preimplantation embryos. Ever since the inception of the formulated synthetic oviductal fluid (SOF) based on the biochemical analysis of sheep oviduct (Tervit et al., 1970), it has become a popular medium of choice. Interestingly, its use as an "all in one medium" for oocyte maturation, fertilization and embryo development was reported successful (Gandhi et al., 2000).

In our laboratory, TCM-199 medium $+10 \%$ FCS+gonadotropins and epidermal growth factor was used for oocyte in vitro maturation, BO medium (Brackett and Oliphant, 1975) for in vitro fertilization and modified synthetic oviductal fluid (mSOF: Takahashi and First, 1992) for embryo culture, each of which have varying concoctions of media substrates, ions and energy substrates. The objective of this study was to evaluate SOF as a common base media for maturation, fertilization and culture for bubaline.

\section{Materials and Methods}

\section{Reagents and media}

Unless specified, all chemicals, reagents and hormones were purchased from Sigma (St Louis, MO, USA). The composition of the base medium-synthetic oviductal fluid for SOF-IVM and SOF-IVF is $99.7 \mathrm{mM}$ $\mathrm{NaCl}, 7.16 \mathrm{mM} \mathrm{KCl}, 1.19 \mathrm{mM} \mathrm{KH}_{2} \mathrm{PO}_{4}, 1.71 \mathrm{mM}$ $\mathrm{CaCl}_{2} \cdot 2 \mathrm{H}_{2} \mathrm{O}, 0.49 \mathrm{mM} \mathrm{MgCl} \cdot 6 \mathrm{H}_{2} \mathrm{O}$. The components of mSOF base media for embryo culture (IVC) is $107.7 \mathrm{mM} \mathrm{NaCl}, 7.16 \mathrm{mM} \mathrm{KCl}, 1.19 \mathrm{mM} \mathrm{KH} \mathrm{PO}_{4}$, $1.71 \mathrm{mM} \mathrm{CaCl}{ }_{2} \cdot 2 \mathrm{H}_{2} \mathrm{O}, 0.49 \mathrm{mM} \mathrm{MgCl} 2 \cdot 6 \mathrm{H}_{2} \mathrm{O}$.

\section{Oocyte collection}

Bubaline ovaries were obtained from a local abattoir and transported to the laboratory within $5 \mathrm{~h}$ in a thermos with $0.9 \%$ saline solution. Cumulus cell-oocyte complexes (COCs) were aspirated from antral follicles (3-5 $\mathrm{mm}$ in diameter) using an 18 gauge needle attached to a sterile $10 \mathrm{ml}$ plastic syringe (Group 1). Also, COCs were collected by ovum pick up using transvaginal ultrasound-guided follicular aspiration (TUFA) of antral follicles measuring 5-12 $\mathrm{mm}$ in diameter from Bulgarian Murrah buffaloes (8-15 yrs old) stationed at the Philippine Carabao Center-Gene Pool (Group 2). Selected COC's from each group were randomly cultured in culture system A or in culture system B which is briefly outlined below in Table 1 .

\section{In vitro maturation of COCs}

Selected oocytes were cultured in the maturation media for $22 \mathrm{~h}$ in a humidified incubator with $5 \% \mathrm{CO}_{2}$ level at $38 \pm 1{ }^{\circ} \mathrm{C}$ in atmospheric air. The IVM media were supplemented with $10 \%$ foetal calf serum $(\mathrm{FCS}, \mathrm{v} / \mathrm{v})$, follicle stimulating hormone $(\mathrm{FSH}, 0.02$ units $/ \mathrm{ml}$ ), epidermal growth factor (EGF, $10 \mathrm{ng} / \mathrm{ml}$ ) and oestradiol $(1 \mu \mathrm{g} / \mathrm{ml})$. After the in vitro maturation period, the oocytes were subjected to fertilization in vitro.

\section{Sperm preparation, in vitro fertilization and culture}

Locally processed frozen semen of water buffaloes from the Sperm Processing Unit of the Philippine Carabao Center stationed at Digdig Ranch, Carranglan, Nueva Ecija were used for in vitro fertilization. For each experimental trials, a straw containing $0.5 \mathrm{ml}$ semen were thawed at $39^{\circ} \mathrm{C}$ for $10 \mathrm{sec}$ and washed twice in SOF-Hepes sperm wash medium or in BO medium by centrifugation. After the final wash, the sperm concentration was determined using haemocytometer and was adjusted to $2 \times 10^{6} \mathrm{sperm} / \mathrm{ml}$ concentration.

SOF-IVF medium was supplemented with 6 $\mathrm{mg} / \mathrm{ml}$ BSA-FAF and $10 \mathrm{mM}$ caffeine while the BO medium was supplemented with $6 \mathrm{mg} / \mathrm{BSA}+5 \mathrm{mM}$ theophylline. Each IVF media were filter sterilized with $0.22 \mu \mathrm{m}$ cellulose nitrate. Shortly thereafter, droplets $(25 \mu \mathrm{l})$ from each IVF media were prepared and were added with $25 \mu \mathrm{l}$ of the washed sperm suspension to give a final sperm concentration of $1 \times 10^{6} \mathrm{sperm} / \mathrm{ml}$.

Before sperm-oocyte coincubation commenced, the oocytes were partially and/or completely denuded free of cumulus cells before transferring in the microdroplets of IVF medium to co-incubate with the sperm for at least $6 \mathrm{~h}$ in a humidified incubator at $39^{\circ} \mathrm{C}$; $5 \% \mathrm{CO}_{2}$ in air. After the sperm and oocyte coincubation in each of the culture systems used, the oocytes were denuded free of unwanted sperm still attached in the zona pellucida and cumulus cell debris by repeated pipetting. The presumptive zygotes were then introduced in the microdroplets $(50 \mu \mathrm{l})$ of $\mathrm{mSOF}$ culture medium to allow embryonic development in a humidified incubator with $5 \% \mathrm{CO}_{2}: 5 \% \mathrm{O}_{2}: 90 \% \mathrm{~N}_{2}$ gas atmosphere at $39 \pm 1^{\circ} \mathrm{C}$.

\section{Assessment of maturation, cleavage and cell count}

Oocytes with visible polar body at the end of maturation period were considered to have completed the 1st meiosis (Ocampo et al., 2001a). Cleaved embryos (2- 4 cell stage) progressing to blastocyst stage (7- $8^{\text {th }}$ day) were fixed in $0.75 \mathrm{ml} \mathrm{Na}$ citrate $(2.3 \%)$ solution $+0.25 \mathrm{ml}$ ethanol $+10 \mu \mathrm{l}$ Hoechst $33342(1$ $\mathrm{mg} / \mathrm{ml}$ stock solution dissolved in ethanol) for at least $24 \mathrm{~h}$ in a refrigeration temperature in an Ependorf tube covered with aluminum foil. Then, the blastocysts were mounted on glass slide in glycerol droplets and the cells counted through Fluorescent microscopy (Thouas, 2001). 
Res. Opin. Anim. Vet. Sci., 2016, 6(6): 173-177.

Table 1: Culture system A and B for the culture of slaughterhouse-derived COCs (Group 1 oocytes) and OPU- derived COCs (Group 2 oocytes)

\begin{tabular}{|c|c|c|c|c|}
\hline Culture system & Source of oocytes & $\begin{array}{l}\text { Maturation } \\
\text { media }\end{array}$ & $\begin{array}{l}\text { Fertilization } \\
\text { media }\end{array}$ & $\begin{array}{l}\text { Embryo culture } \\
\text { media }\end{array}$ \\
\hline Culture system A TCM-BO-mSOF & $\begin{array}{l}\text { Group } 1 \\
\text { Group } 2\end{array}$ & TCM 199 & $\mathrm{BO}$ & $\mathrm{mSOF}$ \\
\hline $\begin{array}{l}\text { Culture system B } \\
\text { SOF based: IVM-IVF-mSOF }\end{array}$ & $\begin{array}{l}\text { Group } 1 \\
\text { Group } 2\end{array}$ & SOF- IVM & SOF-IVF & $\mathrm{mSOF}$ \\
\hline
\end{tabular}

Table 2: Developmental competence of bubaline COCs in different culture systems.

\begin{tabular}{llccccc}
\hline Culture & Source of & \multicolumn{4}{c}{ No. of oocytes (\%) } & \multicolumn{2}{c}{ Total } \\
\cline { 2 - 6 } System & oocytes & cultured & matured/ inseminated & cleaved & blastocyst & cell count \\
\hline A & Group 1 & 83 & $69(83.1)^{\mathrm{a}}$ & $41(59.4)^{\mathrm{a}}$ & $9(13.0)^{\mathrm{a}}$ & $98.8 \pm 7.0$ \\
& Group 2 & 77 & $48(62.3)^{\mathrm{c}}$ & $38(79.2)^{\mathrm{b}}$ & $8(16.0)^{\mathrm{a}}$ & $97.3 \pm 8.1$ \\
B & Group 1 & 75 & $62(82.6)^{\mathrm{a}}$ & $39(62.9)^{\mathrm{a}}$ & $10(16.1)^{\mathrm{a}}$ & $102.3 \pm 3.4$ \\
& Group 2 & 82 & $61(74.4)^{\mathrm{b}}$ & $48(78.7)^{\mathrm{b}}$ & $19(31.1)^{\mathrm{b}}$ & $97.6 \pm 7.5$ \\
\hline
\end{tabular}

Culture system A (TCM-BO-mSOF medium); Culture system B (mSOF medium); Group 1 (COCs derived from the slaughter house); Group 2 (COCs derived from living buffalo cows); ${ }^{a, b, c}$ Values with different superscript differ significantly $(\mathrm{P}<0.05)$.

\section{Results and Discussion}

The completion of $1^{\text {st }}$ meiosis (nuclear maturation) of Group 1 oocytes cultured for maturation in culture systems A and B showed no significant difference (82.6-83.1\%) but was significantly higher than Group 2 oocytes (62.3-74.4\%). Following sperm-oocyte coincubation, the resulting cleavage rate of Group 2 oocytes (78.7-79.2\%) was significantly higher than Group 1 oocytes (59.4-62.9\%) in either culture systems used. Lastly, the resulting blastocyst formation rate was highest in Group 2 oocytes maintained in culture system B (31.1\%). The total cell count of blastocyst stage embryos produced in both culture systems had no significant difference (Table 2).

The results obtained showed that the source of the oocytes affects the in vitro maturation and the subsequent embryo development to the blastocyst stage following fertilization. The observed higher nuclear maturation rate of Group 1 oocytes could be attributed to the homogeneity on the quality of oocytes used. Quantitatively, the opportunity to select only good quality oocytes for maturation was higher in oocytes aspirated from the slaughter house derived ovaries than TUFA derived oocytes (Merton et al., 2009; Ocampo et al., 2015). For every OPU session, all recovered COCs were treated as one batch throughout the whole in vitro embryo production system, including oocytes with few cumulus cell enclosures of less than three layers and those with unevenly darkened ooplasm. Recovery of such type of oocytes was difficult to avoid even with the use of the most optimized pressure of $45-50 \mathrm{~mm} \mathrm{Hg}$ through TUFA (Aquino and Ocampo, 2013). The discrepancies in the quality of oocytes used significantly influences the oocytes ability for completion of $1^{\text {st }}$ meiosis. Such observation was similarly observed in other mammals (Yadav et al., 1997; Ocampo et al., 2001b; Merton et al., 2003; Van Wagtendonk-de Leeuw, 2006).
In earlier studies involving bubaline embryos, development to the blastocyst stage in vitro was demonstrated when cultured in ligated rabbit (Chantaraprateep et a., 1989), sheep oviduct (Galli et al., 1998), co-cultured with oviduct epithelial cells and/or cumulus cells (Totey et al., 1992; Madan et al., 1994; Ocampo et al., 2001c), Buffalo Rat Liver cells or Vero cells (Boni et al., 1994, 1999; Gasparrini, 2002). Although the embryotrophic properties of these cells have been demonstrated, the exact role on the acquisition of embryos developmental potential remained unclear. Also, these systems are quite unsuitable for large scale embryo production. In this study, culture system A (TCM-BO-mSOF) and B (mSOF alone) were compared. The highest blastocyst yield observed was from Group 2 oocytes that were matured, fertilized and cultured in SOF base medium, though morphologically showed no difference from blastocyst stage embryos derived from Group 1 of culture system A. In another study, embryos cultured in SOF were reported to be more translucent and have compact cell mass (Gasparrini, 2002). Upon analysis of the total cell count (Fig. 1) of expanded blastocyst stage embryos produced in both culture systems, no significant differences were observed (97.3 38.1 $102.3 \pm 3.4)$. In bovine, SOF medium has similarly been shown to support embryo development following maturation and fertilization (Takahashi and First, 1992; Carolan et al., 1995).

The lower blastocyst yield of Group 1 oocytes was attributed to the follicular source at different stages of growth and atresia. Follicles from ovaries with or without dominant follicles and/or corpus luteum affect oocyte developmental competence in vitro (Baruselli et al., 1997; Nagai, 2001). In contrast, twice a week repeated OPU in buffaloes resets follicular population with a diameter of $>2 \mathrm{~mm}$ to 0 , that results in a new follicular wave characterized by homogenously sized 

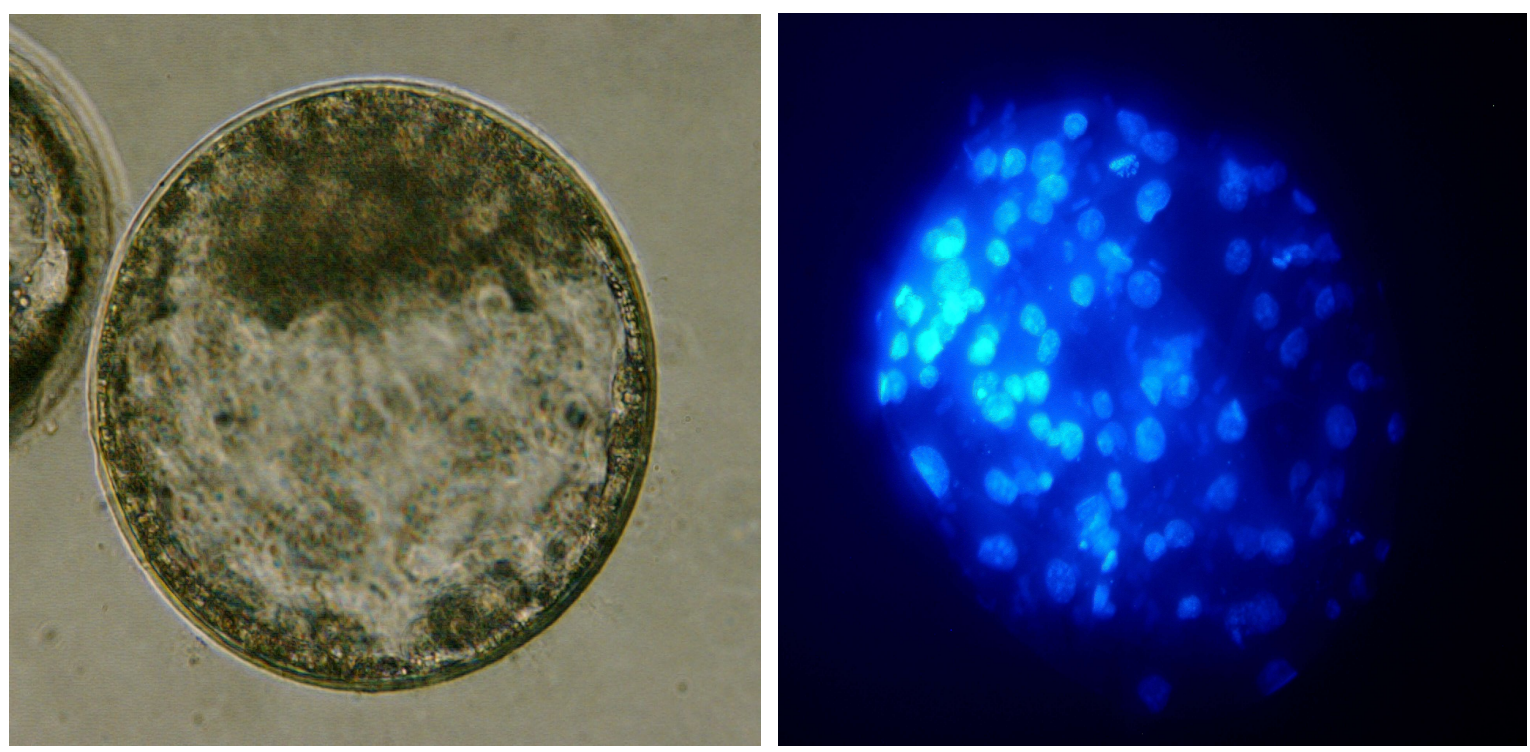

Fig. 1: An expanded blastocyst stage bubaline embryos (Day 7) and its cell count following; Hoechst staining. $400 \mathrm{x}$

follicles (Gasparrini, 2002), with reduced follicular atresia. In this case, the oocytes were recovered before follicular atresia set in, owing to the higher blastocyst yield of Group 2 oocytes. This observation is compatible with the notion that maternally inherited developmental competence (completeness of nuclear and cytoplasmic maturation, DNA synthesis, activation of embryonic genome, polypeptide synthesis and morphological maturation of organelles etc...) plays a major role in controlling the developmental competence of an oocyte or embryos. Also, it was reported that prolonged exposure of buffalo oocytes in excised ovaries (more than $2 \mathrm{~h}$ ) results to cellular damage due to autolytic processes as enhanced by abrupt environmental change (Neglia et al., 2003), significantly compromising the developmental competence of the oocytes/embryos in vitro. Nonetheless, results on the effect of transport time on the maturation, fertilization and embryo developmental rate of swamp buffaloes showed no significant differences (Ocampo et al., 2001b).

\section{Conclusion}

The results of the study showed that bubaline immature oocytes acquisition of developmental competence in the production of blastocyst stage embryos could be achieved in using a single base synthetic oviductal fluid medium.

\section{References}

Aquino F, Atabay ED, Atabay EC, Ocampo MB, Duran P, Pedro P, De Vera RV, Cruz LC (2013) In vitro embryo production and transfer of bubaline embryos using oocytes derived from transvaginal ultrasound guided follicular aspiration. Buffalo Bull 32: 545-548.

Baruselli PS, Mucciolo RG, Visintin JA, Viana WG, Arruda RP, Madureira EH, Oliveira CA, MoleroFilho JR (1997) Ovarian follicular dynamics during the estrous cycle in buffalo. Theriogenology 47:1531-1547.

Boni R, Roviello S, Barbieri V, Zicarelli L (1994) In vitro embryo production in buffalo species. Atti XLVIII Convegno Nazionale SISVET 1:307-312.

Boni R, Roviello S, Gasparrini B, Langella M, Zicarelli $\mathrm{L}$ (1999) In vitro production of buffalo embryos in chemically defined medium. Buffalo J., 1:115-120.

Brackett BG, Oliphant G (1975) Capacitation of rabbit spermatozoa in vitro. Biol Reprod 12:260-274.

Carolan C, Lonergan P, Van Langendonck A, Mermilod P (1995) Factors affecting bovine embryo development in synthetic oviduct fluid following oocyte maturation and fertilization. Theriogenology 43:1115-1128.

Chantaraprateep P, Lohachit C, Techakumphu M, Kobayashi G, Virakul P, Kunayongkrit A, Prateep P, Limsakul A (1989) Early embryonic development in Thai swamp buffalo. Theriogenology 31:1131-1139.

Galli C, Duchi R, Crotti G, Lazzari G (1998) Embryo production by ovum pick-up in water buffalo. Theriogenology 49:400.

Gandhi AP, Lane M, Gardner DK, Krisher RL (2000) A single medium supports development of bovine embryos throughout maturation, fertilization and culture. Human Reprod 15:395-401. 
Gasparrini A (2002) In vitro embryo production in buffalo species: state of the art. Theriogenology 57:237-256.

Madan ML, Chauhan MS, Singla SK, Manik RS (1994) Pregnancies established from water buffalo blastocyst derived from IVM/IVF oocytes cocultured with cumulus and oviduct cells. Theriogenology 42:591-600.

Merton JS, de Roos AP, Mullaart E, de Ruigh I, Kaal I, Vos PI, Dieleman SJ (2003) Factors affecting oocyte quality and quantity in commercial application of embryo technologies in cattle breeding industry. Theriogenology 59:651-674.

Merton JS, Ask B, Onkundi DC, Mullaart E, Colenbrander B, Nielen M (2009) Genetic parameters for oocyte number and embryo production within a bovine ovum pick-up in vitro embryo production program. Theriogenology 72:885-893.

Nagai T (2001) The improvement of in vitro maturation systems for bovine and porcine oocytes. Theriogenology 55:1291-1301.

Ocampo LC, Ocampo MB, Mamuad FV, Venturina EV, Mori T, Shimizu H (2001a) Timing of sequential changes on chromosome configurations during the 1st meiosis, 2nd meiosis and cytoplasmic events of swamp buffalo oocytes matured and fertilized in vitro. Phil $\mathrm{J}$ Vet Anim Sci 27:1-11.

Ocampo LC, Mori T, Mamuad FV, Ocampo MB, Shimizu H (2001b) Maturation and fertilization of swamp buffalo oocytes in vitro; effect of length of ovarian transport. Bubalus bubalis: J Buff Sci Tech 11:68-77.

Ocampo LC, Mamuad FV, Mori T, Shimizu H, Ocampo MB (2001c) In vitro production of pre implantation buffalo embryos. Buffalo J 1:145-154.

Ocampo MB, Ocampo LC (2015) A protocol for the in vitro production of bubaline embryos: The Philippine experience. Intl J Agric Tech., 11(8):2343-2357.

Takahashi Y, First NL (1992) In vitro development of bovine 1- cell embryos: influence of glucose, lactate, pyruvate, amino acids and vitamins. Theriogenology 37:963-978.

Tervit HR, Whittingham DG, Rowson LE (1972) Successful culture in vitro of sheep and cattle ova. J Reprod Fertil 30:493-497.

Thouas GA (2001) Simplified technique for differential staining of inner cell mass and trophectoderm cells of mouse and bovine blastocysts. Reprod Biomed Online 3:25-29.

Totey SM, Singh G, Taneja M, Pawshe CH, Talwar GP (1992) In vitro maturation, fertilization and development of follicular oocytes from buffalo. J Reprod Fertil 95:597-607.

Van Wagtendonk-de Leeuw AM (2006) Ovum pick up and in vitro production in the bovine after use in several generations: A 2005 status. Theriogenology 65:914-925.

Yadav BR, Katiyar PK, Chauhan MS, Madan ML (1997) Chromosome configurations during in vitro maturation of goat, sheep and buffalo oocytes. Theriogenology 47:943-951. 